\title{
Lisht as a New Kingdom glassmaking site with its own chemical signature
}

M. Smirniou (University of Lincoln), Th. Rehren (College of Humanities and Social Sciences, HBKU, Doha, and UCL Institute of Archaeology, London), and B. Gratuze (French National Centre for Scientific Research)

Abstract

Lisht is one of a few New Kingdom sites with known glass-working debris. Here we present evidence for the primary production of glass at Lisht, including crucible fragments and semifinished glass. We also provide 12 new chemical analyses of glass from Lisht, including trace elements. We argue that the glass made at Lisht has a specific chemical signature within the broader range of Late Bronze Age glass compositions from Egypt, further underlining the former existence of primary glass production there and offering the possibility to identify Lisht-made glass elsewhere in Egypt and beyond.

KEYWORDS: glass, glass-making, Egypt, Late Bronze Age, Electron Probe Micro-Analysis, Laser Ablation ICPMS 


\section{INTRODUCTION}

The site of Lisht, famous for its necropolis of the Egyptian $12^{\text {th }}$ Dynasty with numerous royal and elite burials, is situated c $65 \mathrm{~km}$ south of Cairo on the left bank of the Nile. It was established by the first ruler of the $12^{\text {th }}$ Dynasty, Amenemhet I (c.1985 - 1956 BC), and the two major pyramid complexes include his burial and that of his son and successor Senwosret I (Arnold 1988). Excavations from 1906 to 1934 by the Metropolitan Museum of Art in New York (MMA) around the pyramid complexes revealed a settlement site and cemetery (Keller 1983) with continuous occupation from the later Middle Kingdom (c.1875 BC) to the Third Intermediate Period (c.1069 - 664 BC) (dates as presented in Shaw 2003).

This paper examines a set of samples from the New Kingdom strata of the site thought to potentially represent glass-making, building on recent work by the authors on identifying primary glassmaking as opposed to secondary glass-working (Smirniou and Rehren 2011, 2016). Finds of glass waste and slag, fragments of glass vessels, ceramic crucible fragments with glass still attached, blue glass rods and canes, a large blue glass ingot, strings of glass and faience beads and pendants, half-finished glass and faience objects led the excavators to believe that a 'glaze-factory' was situated in the technological complex (Mace 1911, 25). The finds include fragments of crucibles with or without glass still attached, several boxes full with fragments of rods, cullet, and glass waste, and about 200 sherds of glass vessels with evidence of sandy clay core on the inside (Keller 1983; Kozloff et al. 1992). 
The finds from the 'glaze-factory' have been accessioned piecemeal over the almost thirty years that the excavation lasted, and no archaeological context can be attributed to them (Keller 1983). Finds such as scarabs of Seti I (19 $9^{\text {th }}$ Dynasty) as well as those of Ramesses II (19 ${ }^{\text {th }}$ Dynasty) and Sethnakhte $\left(20^{\text {th }}\right.$ Dynasty) were used to date the glass-related activity at the site to an indicated time span from 1295 BC to 1070 BC (Keller 1983).

So far, some of the glass itself has been analysed, but none of the technical or waste material. Brill (1999) performed emission spectrographical analysis on thirteen glass fragments. Mass, Wypyski and Stone (2002) used SEM-EDS to analyse another thirteen glasses from the Lisht complex, mainly to look at the lead and antimony concentration of the yellow and green glasses. Shortland and Eremin (2006) used SEM-WDS to analyse a total of seventeen glasses from Lisht, including the samples that Mass et al. (2002) had analysed previously by EDS, in order to characterise their composition.

\section{IDENTIFYING PRIMARY GLASS-MAKING}

While Lisht has always been considered a candidate for glass production the available evidence only indicates glass-working, and the archaeological record alone is not enough to provide direct evidence of primary glass production. As part of a re-assessment of potential evidence for Egyptian glass-making (Rehren 1997; Rehren and Pusch 2005; Pusch and Rehren 2007; Smirniou and Rehren 2011; Smirniou and Rehren 2016) we analysed eleven previously unstudied samples of production waste (Table 1; Fig. 1) from Lisht to test whether 
they include evidence suggesting primary glass production. The ceramic was examined in order to investigate whether the crucibles were used for glass-making as opposed to glass working, using diagnostic criteria developed by Schoer and Rehren (2007), Merkel and Rehren (2007) and Rehren and Pusch (2008), and recently tested by Smirniou and Rehren (2016). Merkel and Rehren (2007) have shown experimentally that the lime-based parting layer (a lime-rich coating to act as barrier between the glass melt and the ceramic) that is characteristic of crucibles from Egyptian glass works (Turner 1954; Rehren 1997; Schoer and Rehren 2007) reacts with the underlying ceramic in the presence of large amounts of chlorides in the crucible charge to form a buff ceramic zone immediately underneath the parting layer and a pink discoloured zone further into the red ceramic body. Significantly, this sequence of buff and pink zones only forms in the presence of large amounts (roughly 10 wt\% or more: Merkel and Rehren 2007) of chlorides in the crucible batch, but not during the re-melting of already-formed glass. Thus, the presence of a discolouration zone in archaeological ceramics should indicate the presence of about $10 \mathrm{wt} \%$ sodium chloride or more in the crucible charge. The presence of such amounts of salt is thought to be typical of raw materials, particularly plant ash (Brill 1999); hence, the discoloured layer is seen as a strong indication of primary glass-making.

Furthermore, partly-fused material from Lisht was investigated in comparison to semifinished glass identified earlier in Qantir (Rehren and Pusch 2005; Pusch and Rehren 2007) and Amarna (Jackson and Nicholson 2007; Smirniou and Rehren 2011). Criteria to identify semi-finished glass, and hence evidence for glass-making, include the frequent presence of residual quartz grains and newly-formed calcareous crystal phases in an otherwise mostly 
glassy matrix; it is the presence of those newly-formed crystals that differentiate semifinished glass from glassy faience ${ }^{1}$.

\section{THE SAMPLES}

For this study, eleven samples were examined (Table 1). Five of the samples have an MMA accession number, while six were taken from boxes of numerous small fragments without accession numbers.

Most of these seemed to be fragments of glass working debris similar to the well-published material from Amarna (e.g., Shortland and Tite 2000); for this study, we selected those relatively rare fragments that appeared incompletely fused, or had some crucible remains adhering to them. Since most had no accession numbers we allocated fresh numbers beginning with L and MM, during two separate sampling campaigns in 1998 and 2008, respectively. Five samples consisted of glass attached to ceramic fragments - L2.98, L5.98, L1, L2, and L3 (Fig. 1a); two were well-fused glass samples - L10 and MMA11 (L10 is a bicoloured fragment with ceramic remains where both the colourless part L10c and the purple one L10p were analysed, and MMA11 is a large nearly-complete ingot) (Fig. 1b); and four glass waste samples with frothy appearance - MMA2; MMA3; MMA6; MMA8 (Fig. 1c).

\footnotetext{
${ }^{1}$ We use the term glassy faience for faience variant $E$ (Lucas and Harris 1962) as defined by Tite (1987): "glassy faience is very fine textured and consists of unreacted quartz and either wollastonite or devitrite crystals in an essentially continuous glass mixture".
} 
The ceramic parts of three of the above samples - L1, L2, and L3 - have been examined as part of a wider study and shown to be fragments of crucibles employed in glass production (Smirniou and Rehren 2016). Here, we focus on the glass attached and related to those crucibles.

\section{ANALYTICAL TECHNIQUES}

The samples were cut and mounted as polished blocks embedded into epoxy resin or mounted on a glass slide and polished as thin sections using standard sample preparation procedures for microscopic, electron beam and laser ablation analysis. For the ceramic samples, a cross-section of 2 to $4 \mathrm{~cm}$ was cut in order to examine all the underlying layers.

The ceramic samples were photographed both in plane (ppl) and crossed polarised light (xpl) using a Leica DMLM microscope at magnifications from 5x to 50x. This made it possible to directly examine the various phases of the ceramic as well as the interfaces between the glass and the parting layer, and the parting layer and the ceramic.

A Hitachi S3400N SEM was used mainly for its imaging capabilities at magnification from 25x to 2000x. An attached Oxford Instrument energy-dispersive spectrometer (EDS) was used to determine the composition of the crystalline phases and mineral inclusion of the various layers of the samples. 
The JEOL superprobe JXA 8600 at the UCL Institute of Archaeology was used to determine the chemical composition of the glass and ceramic samples. Analyses were conducted at x800 magnification. Corning A glass was routinely analysed at the beginning of each session to check the accuracy of the equipment. Compared to the published data, microprobe analysis of Corning A showed a deviation of only a few percent relative to the published value for most analysed oxides (Table 1). Only for phosphate - with an absolute value of $0.13 \mathrm{wt} \%$ - is JEOL low by nearly $50 \%$ compared to the given value. However, analyses of phosphorus in the Lisht glasses by LA-ICPMS (Table 2) are in close agreement with the values determined by EPMA, with a single exception, suggesting that the low measurement of the Corning A phosphorus value was an anomaly.

The trace elemental analysis was performed by an ablation system consisting of a quadrupled frequency Neodyme:YAG laser operating at $266 \mathrm{~nm}$, coupled with a Thermo Fisher ELEMENT XR mass spectrometer at the National Centre of Scientific Research (CNRS) in Orlèans, France. The samples were first resin mounted and prepared for SEM and EPMA examination, and then analysed with the ablation system.

The ceramic aperture of the laser beam was set to obtain a beam diameter of $80 \mu \mathrm{m}$ and the laser was operated at its maximum energy of 3 to $4 \mathrm{~mJ}$ and at a repetition rate of $7 \mathrm{~Hz}$ (a beam density of 15 to $20 \mathrm{~J} / \mathrm{cm} 2$ ). The signal was acquired for 50 seconds. Two ablation passes were performed and the average was calculated. The National Institute of Standards and Technology (NIST) standard reference materials 610 and 612 along with Corning glass B, C 
and D were used for external standardisation. Reference material Corning glass A was regularly used to check the calibration procedure. Concentrations were calculated according to Gratuze (2013). Using the analytical protocol defined by Gratuze (2013) and adapted to the Element XR mass spectrometer, the detection limits range from $0.01 \%$ to $0.1 \%$ for the major elements, and between 20 and 500 ppb for all the other elements.

\section{TECHNICAL CERAMICS}

We analysed three of the crucible fragments with adhering glass (L1, L2 and L3). All three were made of Nile silt and share common characteristics with very little variability. They are relatively coarse with numerous large sub-angular quartz grains and voids produced by burntout organic inclusions. The similarities in the microstructure and the chemical composition suggest that they were produced using the same raw material, most probably from the same production centre. In cross section, the samples demonstrate a layered structure typical for primary glass-making ceramics (see above and Figs. 3c and 9 in Smirniou and Rehren 2016).

The chemical composition of the buff area is discussed in more detail elsewhere (Smirniou and Rehren 2016). It may suffice here to say that compared to the unchanged Nile silt fabric (Hancock et al. 1986), it is high in lime from the parting layer and also shows high $\mathrm{Cl}$ content. All the Lisht ceramics have high levels of soda, unexpected from Nile silt but very similar to the high soda contents of the Amarna crucibles, possibly due to a gradual build-up of soda concentrations in the ceramic during repeated use (Smirniou and Rehren 2016). 
The three crucible fragments from Lisht share a zoned structure as a result of their use at high temperatures and the presence of a chloride-rich batch, similar to glass-making crucibles from the sites of Qantir and Amarna. The appearance of the zoned structure, confirmed by the analytical data (Smirniou and Rehren 2016), demonstrated that the crucibles from Lisht have been used for primary glass production.

\section{GLASS WASTE - MICROSTRUCTURE}

Most of the glass samples from Lisht are completely fused, non-porous, with smooth appearance and do not show any un-reacted quartz grains. Samples MMA6 and MMA8, however, are quite porous with air bubbles and inclusions, and combine both white and blue glass in each sample. MMA8 has also some areas rich in fused ceramic material. At higher magnification they both demonstrate partially reacted residual quartz grains, semi reacted crystals and various lime-rich phases along with a fully reacted and formed glass matrix (Figs. 2, 3).

Sample MMA6 shows an area (bright white on the edge of the sample) very rich in copper oxide (Cu $79.9 \mathrm{wt} \%$, O $20.1 \mathrm{wt} \%$ as shown by SEM-EDS). This might represent evidence of re-melting the glass batch with the addition of $\mathrm{CuO}$ aiming at producing a blue-coloured glass, where the copper oxide has not been mixed well resulting in an area with pure $\mathrm{CuO}$, areas where the batch was mixed with the copper oxide resulting in formation of blue glass, and areas where the batch did not mix with the copper oxide, resulting in the white or 
colourless glass. The white glass contains also impressions of sodium chloride crystals, a further characteristic of semi-finished glass.

Both samples are interpreted to be semi-finished glass. The quartz grains of MMA8 (Fig. 2) are angular in shape suggesting the use of crushed quartz pebbles. By SEM-EDS several lime-rich crystalline phases with a range of oxide ratios were identified, with devitrite $\left(\mathrm{Na}_{2} \mathrm{Ca}_{3} \mathrm{Si}_{6} \mathrm{O}_{16}\right)$ dominating (Fig. 3).

\section{CHEMICAL COMPOSITION}

\section{Base Glass}

As expected, all samples from Lisht have a typical soda-lime-silica glass composition with elevated contents of magnesia and potash suggesting plant ash as the alkali source (Table 1). The identification of primary glass-making at Lisht raises the questions whether its product can be characterised and identified within the larger corpus of Egyptian glass. Recent work using advanced analytical capabilities has led to the identification of diagnostic trace element pattern to distinguish between Mesopotamian and Egyptian glass (Shortland et al. 2007), and the characterisation of typical Amarna glass, particularly that coloured by cobalt (Smirniou and Rehren 2011). We therefore revisited the existing analyses of Lisht glass, and added some new LA-ICPMS data for the samples studied here (Table 2). Interestingly, there are 
some systematic compositional characteristics shared by most Lisht glasses analysed so far, both on the level of minor oxides and of trace elements, and of the copper colorant used.

Shortland et al. (2007) have shown that the contents of $\mathrm{La}, \mathrm{Cr}$, $\mathrm{Ti}$ and $\mathrm{Zr}$ are distinct enough to distinguish between glasses found in Egypt and those found in Mesopotamia. Plotting the Lisht data into the diagnostic graphs developed by Shortland et al. (2007) shows that they fit with the Egyptian glasses, but with a relatively narrow range of lanthanum, chromium and zirconium at the lower end of the wider Egyptian distribution (Fig. 4a, b).

Calcium and strontium have very similar chemical behaviour, resulting in the good positive correlation of measured values in LBA Egyptian glasses from Amarna, Lisht and Qantir (Fig. 5a). Within the Egyptian data set, the Lisht data plot very close together, at the very low end of the distribution. Studies have shown that the lime content in the glass is mostly determined by the melting temperature of the batch, its composition, and the absorption of the lime-rich parting layer in the melting vessels (Shugar and Rehren 2002; Merkel and Rehren 2007; Rehren 2008; Tanimoto and Rehren 2008). The narrow range of lime content in the Lisht samples, at the low end of Egyptian glass compositions, suggests relatively low melting temperatures and possibly indicates that the reaction vessels and crucibles had no or not as thick a parting layer as the earlier vessels from Qantir and Amarna. Experimental work has shown (Merkel and Rehren 2007; Tanimoto and Rehren 2008) that the lime-rich parting layer that acts as a buffer between the glass melt and the ceramic vessel gets absorbed into the glass melt as the temperature increases, with the maximum lime content in the glass melt rising from $6 \%$ at around $900{ }^{\circ} \mathrm{C}$ to up to $10 \%$ at around $1000{ }^{\circ} \mathrm{C}$ (Rehren 2008). The low 
content of lime of the Lisht samples between $4 \%$ and $5.5 \%$ suggests that either a low furnace temperature of around $800-900{ }^{\circ} \mathrm{C}$ was used, or the glass makers at Lisht applied a low lime plant ash, or a thinner parting layer, or any combination of these three factors. The description of the Lisht glass as less well fused and of inferior quality than finished glass found at the sites of Amarna or Malkata (Keller 1983) is consistent with a suggested lower melting temperature, which would result in a low-lime glass regardless of the original lime content of the batch.

In addition to low lime, most Lisht glasses also have relatively low levels of alumina and iron oxide compared to glasses from elsewhere in Egypt, and relatively high soda levels. The separation is not as clear as for the lime concentrations, but still remarkably consistent. As a result of these lower levels of minor oxides the silica and soda concentrations are typically at the higher end of the range of Egyptian glass, and with a relatively narrow range of values (Table 1); the exception is the white glass L3, which has higher alumina, iron oxide, and related trace elements and therefore differs from the main Lisht cluster.

\section{Coloured Glass}

A total of 42 glass samples have been analysed from Lisht; twelve by the present study and thirty previously (Brill 1999; Mass et al. 2002; Shortland and Eremin 2006). Most of them are copper blue (40\% of the total samples), followed by yellow (17\%) and white (14\%). There are three black and three brown samples, two purple, two colourless and one green. 
The absence of cobalt-coloured glass is notable, given the prominence of cobalt-blue glass elsewhere in Egypt.

Earlier research had identified that most Egyptian copper-blue glass has elevated tin concentrations, of just under one tenth of the copper content, suggesting that it was coloured using bronze scrap as the copper source (Kaczmarczyk and Hedges 1983; Shortland 2000; Shortland and Eremin 2006). In contrast, copper-blue glasses from Mesopotamia have no elevated tin concentrations, suggesting the use of pure copper as the colourant (Shortland and Eremin 2006; Shortland et al. 2007). Against this background more than half (four out of seven) of the copper-blue samples from Lisht contain no or very low levels of tin (Fig. 5b), again highlighting the particular character of the Lisht glass already indicated by the data in Shortland and Eremin $(2006)^{2}$. Four of the seven copper-blue glasses have elevated lead content, of 250 to $500 \mathrm{ppm}$, which we believe is due to the lead content of the copper or bronze metal used as colourant. Only the two semi-finished glasses combining white and blue (MMA6 and 8) contain also elevated antimony reaching around $1 \mathrm{wt} \%$, indicating its use as opacifier.

Samples MMA2 and L3 are visually white and MMA3 is light aqua; of these, the two glass droplets MMA2 and 3 are compositionally very similar and could well come from the same production event, allowing for some internal heterogeneity particularly at the alkalis. Both appear to be high-quality glass with no addition of or contamination from any colourant, or opacifier. The white colour of MMA2 is probably due to a combination of small air bubbles.

\footnotetext{
${ }^{2}$ Shortland and Eremin (2006) report 29 copper-blue glasses from Malkata and Amarna, 20 of which have tin content consistent with bronze use; in contrast, only one out of their six Lisht copper-blue glasses is high in tin.
} 
The thin white glass layer in the crucible base L3 is dense high-quality glass free of any colourant or opacifier; its white appearance is due to the growths of newly-formed crystals at the interface between the parting layer and the glass itself (Fig. 6). Interestingly, it has a very distinct composition from all other samples from Lisht, both at the level of its soda content and minor oxides, and in the trace elements, setting it apart from the main group of Lisht samples (Tables 1,2).

Sample L10 finally had two different glass layers; a colourless layer next to the crucible ceramic, and a purple layer above this. The EPMA analyses clearly show that both layers have the same composition, within the narrow range of analytical error, apart for their manganese content, which is significantly higher in the purple layer and goes along with a slightly increased barium content (Tables 1,2 ). The very high chromium concentration in the colourless glass is probably a local inhomogeneity, and not likely to be representative of all of the colourless glass in this layer.

\section{DISCUSSION}

Remains of glass waste, glass canes and rods, and a large glass ingot along with numerous fragments of finished objects have identified a New Kingdom glass workshop at the site of Lisht, raising also the possibility of local glass production. Fragments of glass objects from the site have been analysed before (Brill 1999; Mass et al 2002; Shortland and Eremin 2006), 
identifying the raw materials and certain elements of the colouring agents. Keller (1983) visually examined finished objects from Lisht, describing the glass as less well fused and of inferior quality than finished glass found at the sites of Amarna or Malkata.

This study focussed on the production waste from Lisht, testing whether there is evidence for primary glass-making in addition to the obvious glass working finds. Most of the glass samples analysed by us are fully fused with no apparent inclusions or intermediate crystals. Two samples, however, contained partially reacted quartz grains and lime-rich phases. Visually and morphologically both samples look different to the semi-finished glass found at the sites of Amarna and Qantir; both are smaller fragments, do not look as porous and frothy, and have far fewer bubbles and un-reacted quartz grains. Despite these differences in detail, we take the presence of partially reacted quartz grains, of various lime-rich intermediate phases and of negatives of sodium chloride crystals to identify these finds as semi-finished glass and therefore evidence for primary glass production, rather than devitrified glass waste from glass working.

Strong evidence for primary glass-making comes also from the study of the technical ceramics, in particular cylindrical crucibles that had been used for glass-making or glassmelting. All analysed ceramics demonstrated diagnostic features of primary glass production, in common with those from Amarna and Qantir, such as the discolouration and chemical contamination due to sodium chloride in the primary batch (Smirniou and Rehren 2016). 
The technical evidence for primary glass-making at Lisht is further corroborated by the composition of the glass from the site. They have a diagnostic Egyptian trace element composition according to criteria developed by Shortland et al. (2007), and match the existing body of analysed Egyptian glasses in all other aspects. However, the Lisht samples have a relatively narrow range of most major, minor and trace element concentrations, including a low zirconium concentration, setting them apart from most other Egyptian glasses. This, and the much narrower range than seen in glasses from the Egyptian sites of Amarna and Malkata, suggest that the Lisht glass samples were produced in a particular production centre. It is significant here to note that the two semi-fused samples match this chemical profile of the other samples from Lisht, indicating that this particular glass was indeed produced locally. Figure $4 \mathrm{~b}$ shows an interesting pattern of trace element distribution within the Egyptian glasses. The majority of those from Malkata plot together with most published Uluburun glasses at relatively high and dispersed levels of both zirconium (35 to $80 \mathrm{ppm}$ ) and titanium (300 to $1200 \mathrm{ppm}$ ), while most Qantir samples plot together at 20 to 30 ppm Zr and 200 to 250 ppm Ti. Only a few Malkata glasses fall next to the Mesopotamian field, with the Lisht glass. The Amarna glasses fall about evenly with the Malkata samples and the Lisht glasses; the latter include the semi-finished Amarna glasses (see Smirniou and Rehren 2011). This broad pattern could indicate the presence of different primary workshops making glass, with some secondary studios receiving most of its glass from just one of these primary producers, while others receive glass from several. A fuller exploration of this emerging pattern is beyond the scope of this paper, but may provide further insight into the internal organisation of the Egyptian glass industry. 
It had been argued elsewhere that the diagnostic trace elements potentially reflect the stone tools used to crush and grind the quartz pebbles used in glass-making (Rehren and Pusch 2007; Rehren 2016). The low levels of minor and trace elements likely to come from the stone tools, such as aluminium, iron, zirconium and others, could indicate that the grinding tools used to produce these glasses were made from quartzite rather than the more common granite or diorite (Rehren and Pusch 2007: 225). The similarity in trace element content of semi-finished glass from Amarna and Lisht could then be due to the use of similar stones for the grinders in Amarna and Lisht, respectively. Alternatively, if semi-finished glass and crucibles with glass adhering were moved between workshops, then this chemical similarity could indicate that the two assemblages of semi-finished glass originate from the same workshop, whether in Amarna, Lisht, or elsewhere.

In contrast to the minor and trace element pattern, we favour a technical explanation rather than a raw material explanation for the low lime content of the Lisht glasses. This suggests that either a low furnace temperature was used for the glass melting, or a thinner lime-rich coating was used to act as a buffer between the ceramic vessel and the glass melt, or both. Several samples that have the ceramic still attached on the glass do not show any signs of the parting layer; the blue ingot found on the site demonstrates chisel marks (Fig. 1b, MMA11) suggesting there must have been an effort to remove it from the ceramic crucible, possibly because there was no or no sufficient parting layer present facilitating the removal of the finished glass cake. It is also possible that the plant ash, the main source of lime in the glass, had less lime than that used at other sites in Egypt. However, the low quality of the glass, containing air bubbles and demonstrating insufficient fusion (Keller 1983) is strong 
indication of a low furnace temperature, which would have limited the lime content of the final glass regardless of the batch composition (Shugar and Rehren 2002; Tanimoto and Rehren 2008).

Taken together, we assert that the glass factory at Lisht produced glass of a characteristic composition reinforcing the initial suggestion by Shortland and Eremin (2006). This composition reflects the combined effects of raw materials, tools, and operating conditions, that is a unique, particular and chemically recognizable smelting system. A similar but different system has been identified at Amarna, with characteristically low potash concentrations and elevated alumina contents, and a strong preference for cobalt-blue glass (Smirniou and Rehren 2011).

As in Amarna with its preference for cobalt-blue glass, this particular signature of Lisht glass extents also to the colouration. The majority of the glass found at the site of Lisht is copper blue, followed by yellow and white, while there does not seem to be any cobalt-blue glass present, a common colour in most other Egyptian sites. The amount of colourant added to the yellow glass is systematically lower than that found in other Egyptian yellow glass (Mass et al. 2002), also there are very few glasses at Lisht with antimony added (Shortland and Eremin 2006), while antimony was widely used to add opacity in glass produced in other Egyptian sites. Furthermore, only half of the copper-coloured blue glasses contain significant levels of tin, in common with most Egyptian copper-coloured blue glasses, while the other half does not have elevated contents of tin, in common with light blue glasses from 
Mesopotamia. However, even these samples have the characteristic Egyptian trace element composition, indicating that the craftspeople in Lisht used a different copper source for the production of copper-blue glass than their peers elsewhere in Egypt, and that the tin-free copper-blue glass is not imported from Mesopotamia.

Taken together, the somewhat lesser quality of the glass, the more limited access to exotic ingredients such as antimony or cobalt, and the indication of a lower operating temperature all point to a workshop that had lesser resources available than its peers in the royal palaces at Malkata, Amarna or Pi-Ramesses. At the same time it demonstrates that glassmaking in New Kingdom Egypt was not restricted to royal sites, but may have been more distributed than previously thought.

\section{CONCLUSION}

We have shown that Lisht was indeed a primary glass production centre as well as a secondary production site for artefacts, based on the evidence of glass debris, technical ceramics and semi-finished glass found on site, and further supported by the particular chemical composition of the glass found at Lisht, including two pieces of semi-finished glass.

The narrow compositional range of the analysed Lisht glasses, including semi-finished glass and a range of colours, leads us to postulate their origin from a single production centre, 
combining effects from individual elements of the smelting system to a unique signature. As a result of this, glass from Lisht, although typically Egyptian in composition, demonstrates subtle but significant differences to analysed glass from the sites of Amarna, Malkata and Qantir - Pi-Ramesse. The low lime content and the low quality of the glass from Lisht indicate a lower working temperature than used elsewhere. The difference in trace element concentrations potentially reflect a particular type of stone tools used in processing the raw material, while the less plentiful use of colourants stands in contrast to those available elsewhere in Egypt. At this stage of our research we have to leave it open whether the lower quality of production and the restricted range of colourants is due to the fact that the glass workshop in Lisht does not form part of a royal or palatial complex, in contrast to all other Egyptian glass-making sites, or whether it reflects a general decline in the economic situation in Egypt towards the end of the New Kingdom. It is clear though that the systematic analysis of Bronze Age glass and glass production waste still yields significant new information regarding the LBA glass industry. The emerging pattern of characteristic trace element clusters within the overall Egyptian signature further indicates the presence of multiple glass production sites within Egypt, as well as the regular exchange of glass among these centres to supply the secondary artistic glass studios with a full range of glass colours.

\section{ACKNOWLEDGEMENT}

We are very grateful to Dr. Dorothea Arnold, Mark Wypyski, and the department of Egyptian Art of the Metropolitan Museum of Art in New York for providing the archaeological samples and facilitating access to their collection. The Centre Ernest-Babelon (CNRS, Orléans, France) as well as the Wolfson Archaeological Science Laboratories at the UCL Institute of Archaeology are gratefully acknowledged for their technical support. This work was part of the doctoral research of Melina Smirniou, who would like to thank the 
British Museum and especially Dr. David Saunders, Mr. Nicholas Lee, and her colleagues Tracey Sweek, Amy Drago, Tomasina Munden and the Stone Wall Paintings and Mosaics Conservation section for the support they showed during her doctoral studies. Detailed comments from two reviewers are gratefully acknowledged and have helped us to strengthen the paper; any remaining errors or differences of opinion are our own responsibility.

\section{REFERENCES}

Arnold, D., 1988, The South Cemeteries of Lisht. I. The Pyramid of Senwosret I. New York.

Brill, R.H., 1999, Chemical Analyses of Early Glasses, Volumes 1 (Tables) and 2 (Catalogue), Corning Museum of Glass, Corning, New York.

Gratuze, B., 2013. Glass characterisation using laser ablation inductively coupled plasma mass spectrometry methods. In: Janssens, K.H.A. (ed), Modern Methods for Analysing Archaeological and Historical Glass, John Wiley and Sons Ltd, Chapter 3.1.

Hancock, R.G.V., Millet, N.B., and Mills, A.J., 1986, A rapid INAA method to characterize Egyptian ceramics, Journal of Archaeological Science, 13, 107-117.

Jackson, C.M. and Nicholson, P.T. 2007, Compositional analysis of the vitreous materials found at Amarna, in: Brilliant Things for Akhenaten, London, 101-116.

Jackson, C.M. and Nicholson, P.T., 2010. The provenance of some glass ingots from the Uluburun shipwreck, Journal of Archaeological Science, 37, 295-301.

Kaczmarczyk, A., and Hedges, R.E.M., 1983, Ancient Egyptian faience: An analytical survey of Egyptian faience from predynastic to Roman times, Warminster, England: Aris \& Phillips.

Keller, C. A., 1983, Problems of dating glass industries of the Egyptian New Kingdom: examples from Malkata and Lisht, Journal of Glass Studies, 25, 19-28.

KOZLOFF, A./BRYAN, B./BERMAN, L., 1992, Egypt's Dazzling Sun, Amenhotep III and his world. Bloomington.

Lilyquist, Chr. and Brill, R.H., 1993, Studies in Early Egyptian Glass. New York, NY: Metropolitan Museum of Art. 
Lucas, A., and Harris, J. R., 1962, Ancient Egyptian Materials and Industries, 4th edn, Edward Arnold, London.

Mace, A., 1911, The Metropolitan Museum of Art Bulletin, 6.1, Supplement: The Murch Collection of Egyptian Antiquities (Jan., 1911), 1-28.

Mass, J. L., Wypyski, M. T., and Stone, R. E., 2002, Malkata and Lisht glassmaking technologies: towards a specific link between second millennium BC metallurgists and glassmakers, Archaeometry, 44, 67-82.

Merkel, S., and Rehren, Th., 2007, Parting layers, ash trays, and Ramesside glassmaking: an experimental study, in Rubinglas für den Pharao-Hochtemperatur-Technologie in der Ramses-Stadt (=Forschungen in der Ramsesstadt, 6) (eds. E. B. Pusch and Th. Rehren), 201-21, GerstenbergVerlag, Hildesheim.

Pusch, E.B., and Rehren, Th., 2007, Rubinglas für den Pharao-Hochtemperatur-Technologie in der Ramses-Stadt (=Forschungen in der Ramsesstadt, 6), Gerstenberg-Verlag, Hildesheim.

Rehren, Th., 1997, Ramesside glass-colouring crucibles, Archaeometry, 39, 355-68.

Rehren, Th., 2008, A review of factors affecting the composition of early Egyptian glasses and faience: alkali and alkali earth oxides, Journal of Archaeological Science, 35, 1345-54.

Rehren, Th., 2016, Another order for glass - or how much glass does Pharaoh need? In: H. Franzmeier, Th. Rehren and R. Schulz (eds), Mit archäologischen Schichten Geschichte schreiben (=Forschungen in der Ramses-Stadt, 10), Gerstenberg-Verlag, Hildesheim, 163-175.

Rehren, Th., and Pusch, E.B., 2005, Late Bronze Age glass production at Qantir-Piramesses, Egypt, Science, 308, 1756-8.

Rehren, Th., and Pusch, E.B., 2007, Glas für den Pharao-Glasherstellung in der Spätbronzezeit des Nahen Ostens, in Einführung in die Archäometrie (ed. G. Wagner), 215-35, Springer-Verlag, Heidelberg.

Rehren, Th. and Pusch, E.B., 2008, Crushed rock and molten salt? Some aspects of the primary glass production at Qantir/Pi-Ramesse. In: C.M. Jackson and E.C. Wager (eds), Vitreous Materials in the Late Bronze Age Aegean, 14-33, colour plates 2.1-2.11. Sheffield Studies in Aegean Archaeology, Oxbow, Oxford. 
Schoer, B., and Rehren, Th., 2007, The composition of glass and associated ceramics from Qantir, in Rubinglas für den Pharao-Hochtemperatur-Technologie in der Ramses-Stadt (=Forschungen in der Ramsesstadt, 6) (eds. E. B. Pusch and Th. Rehren), 171-99, Gerstenberg-Verlag, Hildesheim.

Shaw, I., 2003, The Oxford history of ancient Egypt, Oxford University Press, Oxford.

Shortland, A. J., 2000, Vitreous materials at Amarna, British Archaeological Reports International Series 827, Archaeopress, Oxford.

Shortland, A. J., 2002, The use and origin of antimonate colorants in early Egyptian glass, Archaeometry, 44, 517-30.

Shortland, A. J., and Eremin, K., 2006, The analysis of second millennium glass from Egypt and Mesopotamia, part 1: new WDS analyses, Archaeometry, 48, 581-603.

Shortland, A. J., Rogers, N., and Eremin, K., 2007, Trace element discriminants between Egyptian and Mesopotamian Late Bronze Age glasses, Journal of Archaeological Science, 34, 781-9.

Shortland, A. J., and Tite, M. S., 2000, Raw materials of glass from Amarna and implications for the origins of Egyptian glass, Archaeometry, 42, 141-51.

Shugar, A., and Rehren, Th., 2002, Formation and composition of glass as a function of firing temperature, Glass Technology, 43C, 145-50.

Smirniou, M., 2012, Technical Investigation of Late Bronze Age glass production in Egypt and the Eastern Mediterranean, PhD Thesis, UCL Institute of Archaeology, University of London.

Smirniou, M., and Rehren, Th., 2011, Direct evidence of primary glass production in Late Bronze Age Amarna, Egypt, Archaeometry 53, 58-80.

Smirniou, M., and Rehren, Th., 2013, Shades of blue - cobalt-copper coloured blue glass from New Kingdom Egypt and the Mycenaean world: a matter of production or colourant source?, Journal of Archaeological Science, 40, 4731-43.

Smirniou, M., and Rehren, Th., 2016, The use of technical ceramics in early Egyptian glass-making. Journal of Archaeological Science 67, 52-63. 
Tanimoto, S., and Rehren, Th., 2008, Interaction between silicate and salt melts in LBA glassmaking, Journal of Archaeological Science, 35, 2566-73.

Turner, W. E. S., 1954, Studies in ancient glass and glassmaking processes, part I. Crucibles and melting temperatures employed in ancient Egypt at about 1370 B.C. Journal of the Society of Glass Technology, 38, 436-44.

Vicenzi, E.P., Eggins, S., Logan, A., and Wysoczanski, R., 2002. Microbeam characterization of Corning archaeological reference glasses: new additions to the Smithsonian Microbeam standard collection. Journal of Research of the National Institute Standards and Technology 107, 719-727.

\section{CAPTIONS}

Fig. 1: Samples from the site of Lisht analysed in this study - from the Metropolitan Museum of Art in New York.

Fig. 2: BSE image of sample MMA8, showing partly corroded glass (light and mid grey with residual angular quartz particles (darker grey).

Fig. 3: BSE image of sample MMA8, showing clusters of lime-rich residual material (light grey, irregular) and some newly-formed large crystals (light grey, indicated by arrows).

Fig. 4a: La vs Cr plot of Lisht glasses (green squares) and other Egyptian and Mesopotamian glasses. The Lisht glass clusters within the low-concentration range of the Egyptian glass. 4b: Zr vs Ti plot of the same glasses. The Lisht glasses, except L3, plot again at a narrow range away from most other Egyptian glasses, but with several of the Amarna glasses. Note also the tight cluster of most of the Qantir glasses (red circles, with low Ti values), and the generally elevated values for most Malkata and Uluburun glasses, and some Amarna samples. Comparative data from: Shortland et al. (2007); Jackson and Nicholson (2010); Smirniou (2012), partly published in Smirniou and Rehren (2011); own unpublished LA-ICPMS analyses of glass from the site of Qantir. 
Fig. 5a: Sr vs $\mathrm{CaO}$ plot of Lisht glasses (green squares) and those from Amarna and Qantir. Note the tight cluster of the Lisht samples, again with the exception of L3, and the generally good positive correlation between the two compounds. Comparative data from Shortland et al. (2007); Smirniou (2012), partly published in Smirniou and Rehren (2011); own unpublished LAICPMS analyses of glass from the site of Qantir.

5b: $\mathrm{Cu}$ vs $\mathrm{Sn}$ plotof Lisht samples, showing the presence of tin only in about half of the samples. The straight line represents the ratio of 1:10 Sn:Cu, approximating typical Bronze Age tin bronze composition. Comparative data from Shortland and Eremin (2006).

Fig. 6: BSE image of cross section through the glass layer in sample L3; the glass (upper part) is colourless transparent, while the abundant growth of newly-formed crystals (centre, darker grey in BSE contrast) at the interface to the parting layer and ceramic (bottom) make it appear white to the eye.

Table 1: Major and minor oxide concentrations in wt \% of the Lisht samples analysed here, as determined by EPMA. For comparison, the analytical results of Corning A glass are also provided. Blue-coloured samples are at the top, followed by the purple sample and the uncoloured / white-appearing samples. L3 at the bottom is an outlier.

Table 2: Selected trace element concentrations in ppm of the Lisht glasses, as determined by LA-ICPMS. 